Supporting Information for:

\title{
Lithium Polyniobates. A Lindqvist-Supported Lithium-Water Adamantane Cluster and Conversion of Hexaniobate to a Discrete Keggin Complex
}

\author{
Travis M. Anderson ${ }^{\S}$, Steven G. Thoma ${ }^{\S}$, François Bonhomme ${ }^{\S,}$, Mark A. \\ Rodriguez $^{\S}$, Hyunsoo Park ${ }^{\ddagger}$, John B. Parise ${ }^{\ddagger}$, Todd M. Alam ${ }^{\S}$, James P. Larentzos ${ }^{\S}$, \\ and May Nyman ${ }^{\S}$
}

${ }^{\S}$ Sandia National Laboratories, P. O. Box 5800, Albuquerque, New Mexico 87185

${ }^{\ddagger}$ Department of Chemistry, Department of Geosciences, Center for Environmental Science, SUNY, Stony Brook, Stony Brook, NY, 11794

"Present address: Ecole Centrale de Paris, Laboratoire SPMS, 92295 ChatenayMalabry, France

\section{Table of Contents:}

Figure S1. Thermal ellipsoids plots for complex 1 (left) and complex 2 (right).

Figure S2. (Top) ${ }^{7} \mathrm{Li}$ MAS NMR of 1 . (Bottom) ${ }^{6} \mathrm{Li}$ MAS NMR of $\mathbf{1}$.

Figure S3. (Top) ${ }^{7} \mathrm{Li}$ MAS NMR of 2. (Bottom) ${ }^{6} \mathrm{Li}$ MAS NMR of 2.

Figure S4. Connolly surfaces for the five void spaces located in $\mathbf{2}$.

Table S1. Coordinates for the centers of mass of the five void spaces located in 2. 
Figure S1.
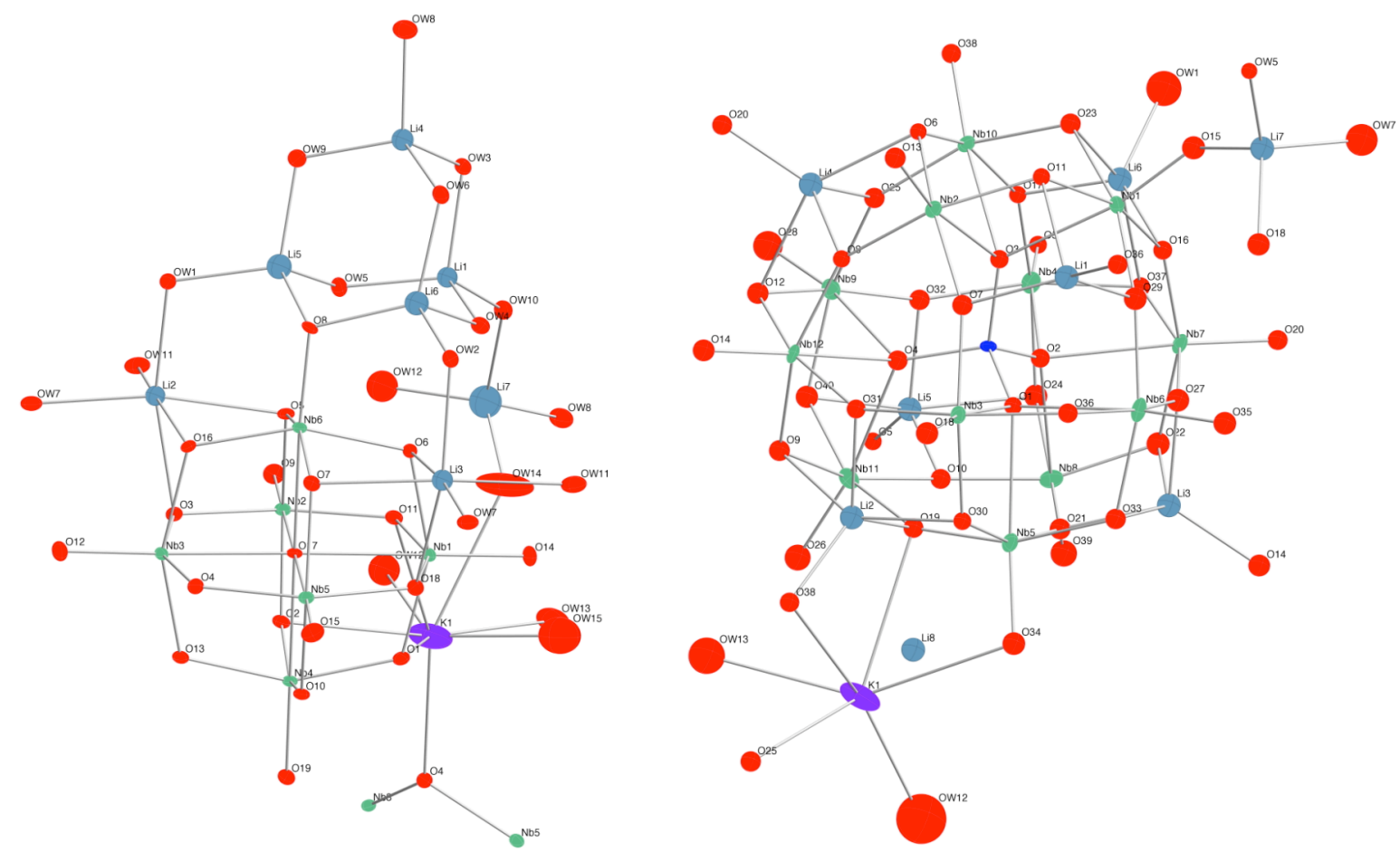
Figure S2.
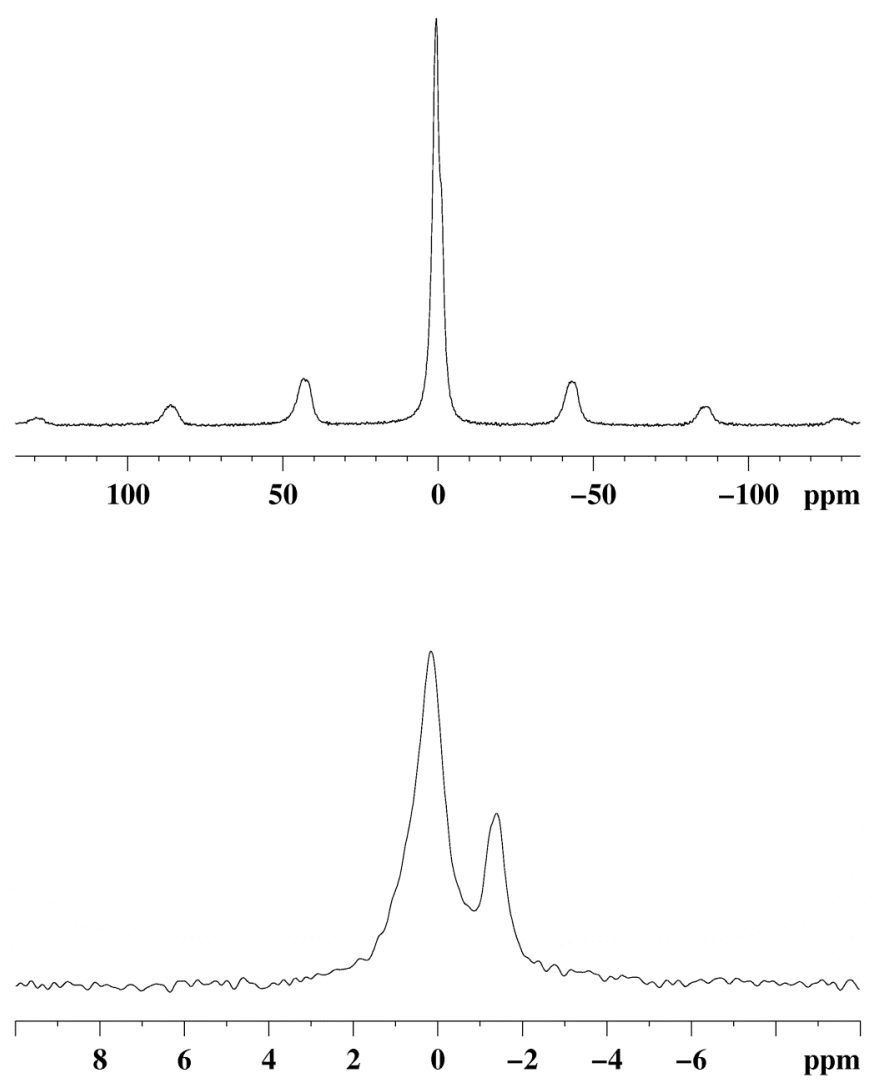
Figure S3.
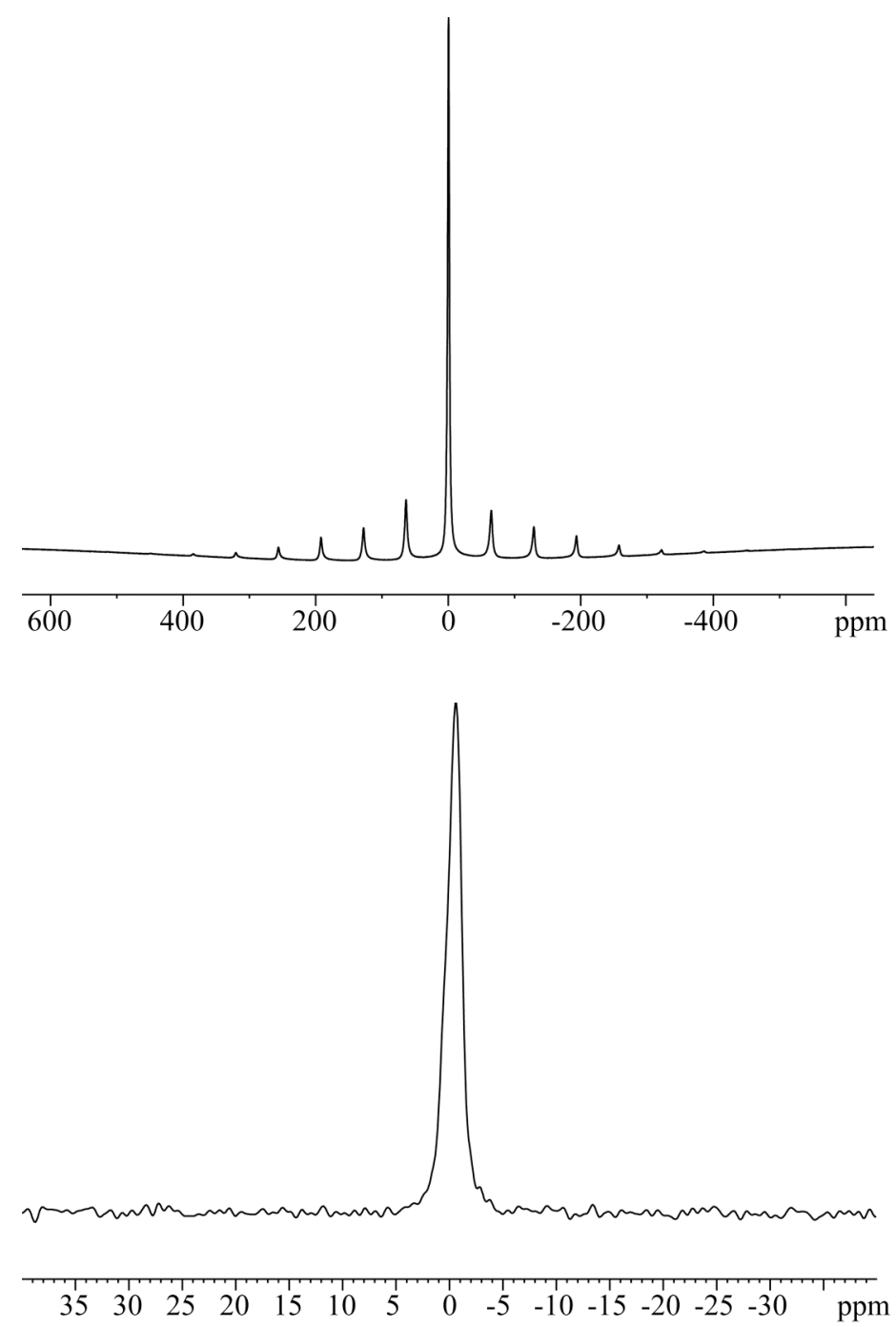
Figure S4.

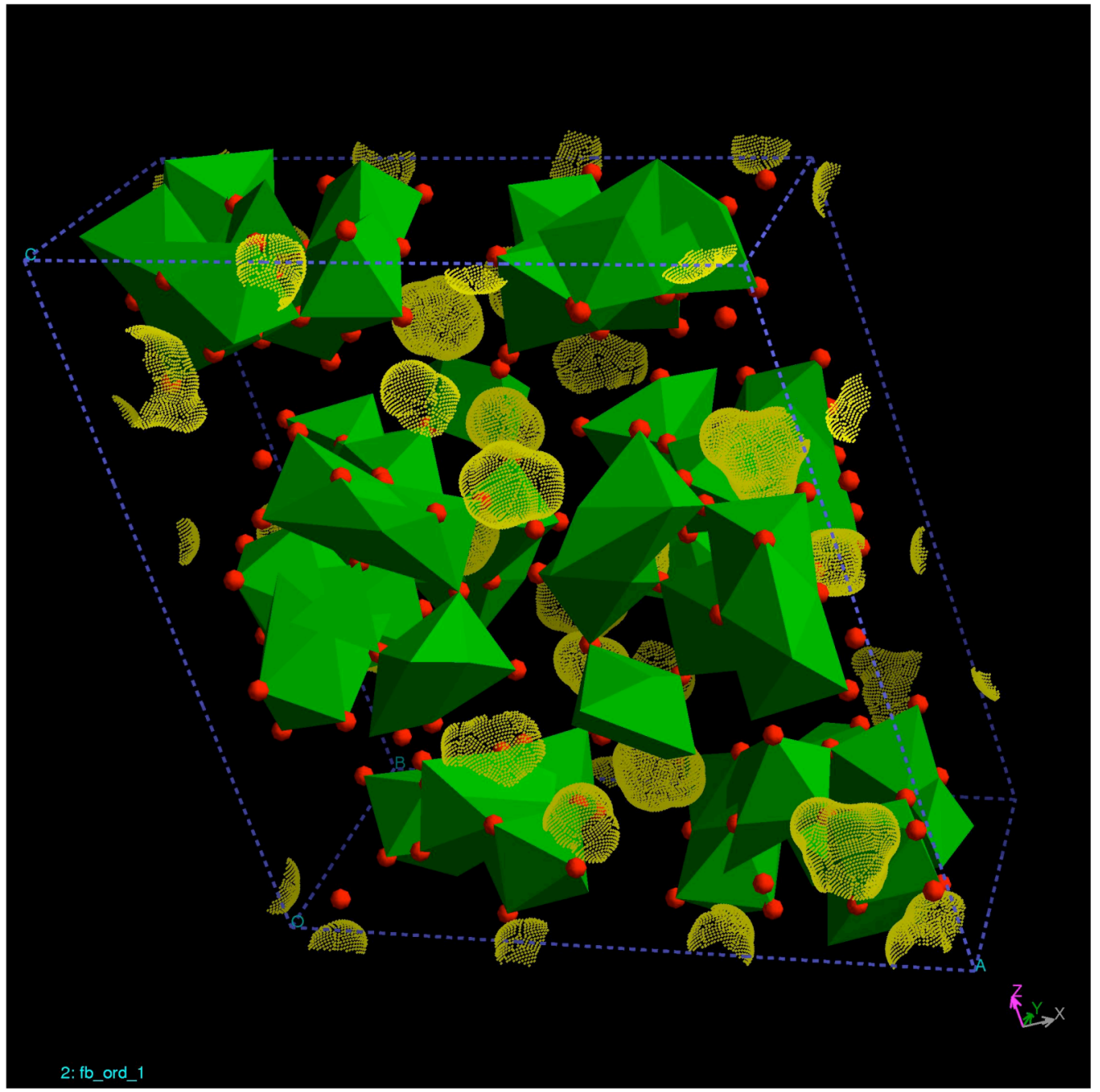


Table S1. Coordinates for the centers of mass for each of the five void spaces located in $\mathbf{2}$.

\begin{tabular}{|c|c|c|c|}
\hline Site & $\mathrm{x}$ & $\mathrm{y}$ & $\mathrm{z}$ \\
\hline Void 1 & 0.07334 & 0.88451 & -0.01547 \\
\hline Void 2 & 0.13861 & -0.06302 & 0.84055 \\
\hline Void 3 & 0.36081 & -0.04728 & -0.00291 \\
\hline Void 4 & 0.43704 & -0.08707 & 0.32480 \\
\hline Void 5 & 0.50267 & 0.01912 & 0.18898 \\
\hline
\end{tabular}

